\title{
Hierarchical control of offshore wind farm connected by parallel diode-rectifier based HVDC and HVAC links
}

\author{
Lujie $\mathrm{Yu}^{1}, \mathrm{Rui} \mathrm{Li}^{1 *}, \mathrm{Lie} \mathrm{Xu}^{1}$ \\ ${ }^{1}$ Department of Electronic and Electrical Engineering, University of Strathclyde, G1 1XW, Glasgow, UK \\ rui.li@strath.ac.uk
}

\begin{abstract}
This paper investigates the operation of offshore wind farm connected by parallel diode-rectifier based HVDC (DRHVDC) and HVAC links. A secondary voltage control is proposed to control the offshore AC voltage amplitude by regulating the DC voltage of the DR-HVDC link. A secondary frequency control and a phase angle control are proposed to adjust the reactive power reference in the primary control, which synchronise the offshore point of common coupling (PCC) frequency and phase angle to those of the HVAC link. Such secondary voltage control, frequency control and phase angle control enable seamless transition from DR-HVDC mode to parallel mode. A tertiary power control scheme is further proposed to control the active power flow distribution between DR-HVDC and HVAC links through the regulation of PCC phase angle. To ensure smooth transition from HVAC mode to parallel mode, a virtual DC power control is proposed to control the virtual DC power at zero prior to the connection of the DR-HVDC link. A small-signal model of the parallel system is developed and the stability analysis is carried out for the proposed control scheme. Simulation results in PSCAD/EMTDC verify the proposed control under normal and fault conditions.
\end{abstract}

\section{Introduction}

Increased installation of large offshore wind power plants located far from onshore connection point requires reliable and efficient transmission technology. Recently, diode-rectifier based high voltage direct current (DR-HVDC) system, which uses offshore diode rectifier and onshore modular multilevel converter (MMC), has been proposed for offshore wind power transmission [1]-[4]. Compared with MMC based HVDC for offshore wind farm connection, DRHVDC system can potentially lead to significant reductions of offshore converter volume, transmission losses and total cost [1]-[2].

However, unlike offshore MMCs, offshore diode rectifiers are unable to control the offshore frequency and voltage. Thus, WT converters have to behave as grid-forming converters to establish the offshore AC voltage and frequency. A voltage and frequency control of permanent magnet synchronous generator (PMSG) based wind turbines (WTs) is proposed for DR-HVDC system using low bandwidth communication in [3]-[4]. With the same control, the research is extended to efficiency analysis and fault-ride through analysis [5], operation with reduced filter banks [6] and integration of the diode-rectifier in HVDC grids [7]-[8]. The operation of doubly-fed-induction-generator based WTs connected with DR-HVDC is studied in [9] using a centralized active power control to change the offshore PCC voltage. In [10], a fixed-frequency control based on global positioning system (GPS) is proposed to provide a common angular reference for all the WTs, but reactive power sharing among the WTs is not addressed. A decentralized control is proposed in [11] which uses reactive power and frequency droop control to regulate the WT phase angle and achieve equal reactive power sharing. However, WT initial synchronization with the offshore network before deblocking is not considered. A distributed phase-lock-loop (PLL) based WT control [12] is proposed with each WT controlled as an AC voltage source. The offline WTs can be easily synchronized to offshore AC network and WTs can provide offshore AC frequency control autonomously. The fault performances including offshore symmetrical and asymmetrical faults, DC fault and diode-rectifier unit fault are analysed and relevant protection schemes are developed in [13]-[14].

Series connection of diode rectifier and VSC is proposed in [15] to transmit offshore wind power whereas in [16], umbilical AC cables are connected in parallel with DRHVDC link during start-up, in order to energize the offshore network and diode rectifier. However, the umbilical AC cables are disconnected during normal operation, without making full use of the AC cables transmission capability. Parallel operation of DR-HVDC and existing HVAC links is also considered when testing the new DR-HVDC gridconnection solution, such that the DC link can be quickly disconnected in the event of malfunction without losing the entire power [17]. Two different operation modes are investigated under such scheme, i.e. DC mode when the wind farm is only connected with DR-HVDC link and AC mode when only connected with HVAC link. However, the transition between different operation modes is not clarified. In addition, the parallel operation when both DR-HVDC link and HVAC link are connected with the offshore network is not investigated. In [18], the operation switching from parallel mode to AC and DC mode is briefly discussed, but the transition from DC mode to parallel mode is not analysed.

This paper provides detailed investigation of parallel operation of DR-HVDC and HVAC links for connecting large offshore wind farms. The main contributions of the paper are summarized as follows:

○ To ensure seamless transition from DR-HVDC operation mode to parallel AC and DC operation mode, a secondary voltage control is proposed to control the offshore AC voltage amplitude by regulating the DC voltage of the DR-HVDC link, and a secondary synchronization control is proposed to synchronize the frequency and phase angle of the offshore AC network with those of the HVAC link.

- A tertiary power control scheme is proposed to improve the power flow distribution between DR-HVDC and HVAC links under parallel mode. By controlling the 
This paper is a post-print of a paper submitted to and accepted for publication in IET Renewable Power Generation and is subject to Institution of Engineering and Technology Copyright. The copy of record is available at IET Digital Library.

active power through the HVAC and/or the HVDC links, power sharing can be achieved.

- In the transition from HVAC mode to parallel mode, a virtual DC power control is proposed to avoid large transient current of the DR-HVDC link during its connection.

- A small-signal model of the parallel system is developed for analysing stability of the proposed control scheme.
The rest of this paper is organized as follows. The layout and control requirements of the parallel system are described in Section 2. In Section 3, the secondary voltage and synchronization control, tertiary power flow control and virtual DC power control are proposed. In Section 4, the small-signal model of the parallel system is developed and stability analysis is carried out for the proposed control scheme. Section 5 presents simulation results and finally Section 6 draws conclusions.

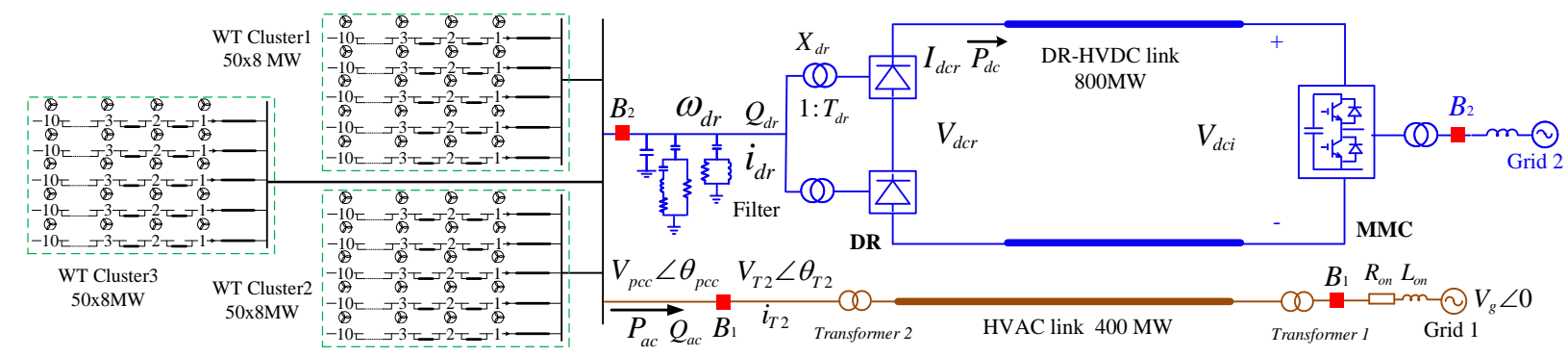

Fig. 1. Diagram of the offshore wind farm connected with DR-HVDC and HVAC transmission system.

\section{Parallel operation of the system}

\subsection{System structure}

Fig.1 shows the layout of the system where the offshore wind farm is connected to both DR-HVDC and HVAC links. The wind farm considered here is rated at 1200 MW and has 3 clusters with each consisting of 50 PMSG based WTs. The power rating of each WT is $8 \mathrm{MW}$. The DRHVDC link uses a 12-pulse diode rectifier offshore and a halfbridge submodule based MMC onshore, rated at $800 \mathrm{MW}$ (two-third of the total wind power) and $\pm 320 \mathrm{kV} \mathrm{DC}$. Capacitors and low-frequency and high-frequency filter banks [19] rated at $240 \mathrm{MVAr}$ are installed at the AC side of the diode rectifier for harmonic filtering and reactive power compensation. The HVAC link is rated at $150 \mathrm{kV}$ and onethird (400MW) of the total wind power, which is connected with the wind farm via an offshore AC transformer. Two independent onshore $\mathrm{AC}$ grids are considered, one for the HVAC link and the other for the DR-HVDC link, similar to the 'Kriegers flak-combined grid solution' project [20]-[21].

\subsection{Operation mode}

Depending on the connection of the transmission links, the system operation modes can be classified as:

- HVAC mode: Wind power is only transmitted through HVAC link while DR-HVDC link is disconnected from the offshore wind farm.

○ DR-HVDC mode: Wind power is only transmitted through DR-HVDC link while HVAC link is disconnected from the offshore wind farm.

- Parallel mode: The offshore wind farm is connected to both DR-HVDC and HVAC links. Wind power can be transmitted through both links according to operation requirements.

\subsection{Control requirements}

To ensure efficient operation under different modes, the control requirements of the parallel system include:

- Wind power generation according to WT operation requirements under all operation modes.

- Establishing offshore voltage and frequency under DRHVDC mode.

- Smooth transition from DR-HVDC mode to parallel mode.
- Smooth transition from HVAC mode to parallel mode.

- Power flow control between DR-HVDC link and HVAC link under parallel mode.

In order to meet the aforementioned operation requirements, a hierarchical control structure which includes primary, secondary and tertiary controls, is proposed in this paper. The primary control provides WT active power and reactive power control under all operation modes and maintains the offshore voltage and frequency on DR-HVDC mode. The secondary control regulates the offshore voltage magnitude, frequency and phase angle to achieve smooth transition from HVAC mode to parallel mode. The tertiary control adjusts the power flow between DR-HVDC link and HVAC link on parallel mode. The detailed function and control will be described in the following sections.

\subsection{Primary control}

The primary control is designed in each WT converter to provide plug and play capability without the use of communication. In addition to transmitting wind power and sharing reactive power among the WTs, this control level is also designed to provide decentralized offshore frequency and voltage control on DR-HVDC mode [3, 12]. In order to achieve smooth transition between different operation modes and to avoid primary control switching, the same WT converter primary control is used for all the operation modes.

Assuming that WT generator-side converters control their DC voltages, Fig. 2 shows the primary control of WT line-side converters in the $d q$ reference frame where the converter filter bus voltage $v_{f}$ is aligned with the $d$ axis [12], which includes:

- Current control to prevent the converters from overcurrent during fault conditions;

- Decentralized offshore AC voltage and frequency control to ensure large numbers of WTs work autonomously to provide $\mathrm{AC}$ voltage and frequency regulation, especially under DR-HVDC mode;

- WT active power control to ensure generated wind power is transmitted to the offshore network;

- WT reactive power control to ensure reactive power is shared among all the WT line-side converters. 
This paper is a post-print of a paper submitted to and accepted for publication in IET Renewable Power Generation and is subject to Institution of Engineering and Technology Copyright. The copy of record is available at IET Digital Library.

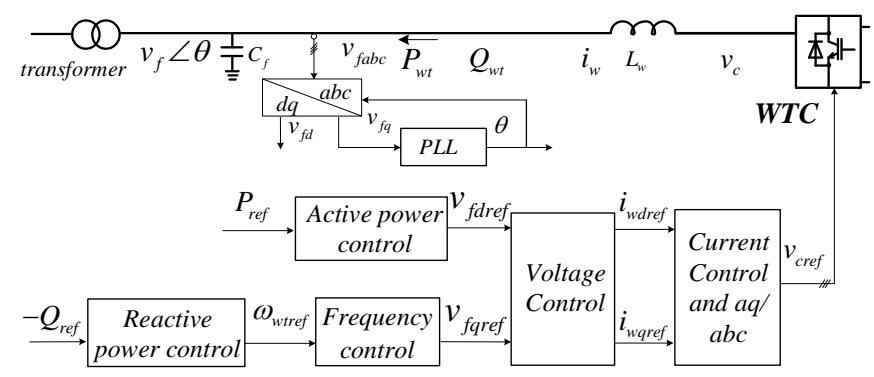

Fig. 2. Primary control of the offshore WT line-side converter.

\section{Proposed secondary control and tertiary control}

\subsection{Voltage and frequency deviation caused by the primary control under DR-HVDC mode}

Under DR-HVDC mode, the relationship between the offshore AC voltage $V_{p c c}$, the DC current $I_{d c r}$ and offshore DC voltage $V_{d c r}$ is expressed as [12]

$$
V_{p c c}=\frac{V_{d c r}}{2.7 T_{d r}}+\frac{3 X_{d r} I_{d c r}}{1.35 T_{d r} \pi}
$$

where $X_{d r}$ and $T_{d r}$ are the reactance and turn ratio of the DR transformer respectively. The offshore DC voltage $V_{d c r}$ and current $I_{d c r}$ are expressed as

$$
V_{d c r}=R_{d c t} I_{d c r}+V_{d c i}, \quad I_{d c r}=P_{w t t} / V_{d c r}
$$

where $P_{w t t}, V_{d c i}$ and $R_{d c t}$ are the total transmitted wind power, onshore DC voltage and total DC resistance, respectively.

Combining (1) and (2), the offshore PCC voltage is rewritten as

$$
V_{p c c}=\frac{V_{d c i}}{2.7 T_{d r}}+\frac{\left(R_{d c t} \pi+6 X_{d r}\right)\left(-V_{d c i}+\sqrt{V_{d c i}{ }^{2}+4 R_{d c t} P_{w t t}}\right)}{5.4 T_{d r} \pi R_{d c t}} .
$$

As can be seen, the minimum offshore PCC voltage when the DR starts conducting is $V_{d c i} / 2.7 T_{d r}$, and $V_{p c c}$ increases when the transmitted wind power $P_{w t t}$ increases.

Reactive power consumption $Q_{d r}$ of the DR is expressed as

$$
Q_{d r}=P_{w t t} \frac{(2 \mu-\sin 2 \mu)}{(1-\cos 2 \mu)}, \mu=\arccos \left(1-\frac{2 X_{d r} I_{d c r}}{T_{d r} V_{p c c}}\right)
$$

Thus, the reactive power consumption of the DR varies with the generated wind power. In order to balance the reactive power in the offshore network, $Q-f$ droop control in the WT primary control is adopted to regulate WT reactive power output [12]-[13]. As a result, the offshore frequency also deviates slightly from the rated value during wind power variation under DR-HVDC mode [3]-[8].

\subsection{Proposed secondary offshore voltage, frequency and phase angle control}

During the transition from DR-HVDC mode to parallel mode, it is important to ensure the matching of the voltage magnitude, frequency and phase angle between the offshore PCC voltage $V_{p c c} \angle \theta_{p c c}$ and HVAC link voltage $V_{T 2} \angle \theta_{T 2}$, before connecting the two AC networks together.

\section{A. Voltage matching}

As described in (3), the offshore PCC voltage $V_{p c c}$ under DR-HVDC mode is dependent on the generated active power $P_{w t t}$ and onshore MMC DC voltage $V_{d c i}$. However, the active power $P_{w t t}$ varies according to wind speed. Thus, in order for the offshore PCC voltage magnitude $V_{p c c}$ to match that of the HVDC link prior to switching to parallel mode (i.e. connecting the HVAC cables to the offshore wind farm), the onshore MMC DC voltage $V_{d c i}$ is adjusted. The proposed secondary offshore voltage control is shown in Fig. 3, where $V_{T 2}$ is the voltage amplitude of the HVAC link and $V_{\text {dcio }}$ is the rated onshore MMC DC voltage. $k_{v p}$ and $k_{v i}$ are the control parameters of the secondary offshore voltage control. The generated onshore DC voltage reference $V_{\text {dciref }}$ is then sent to the onshore MMC by low bandwidth communication to adjust the DC voltage accordingly.

\section{B. Frequency matching}

Due to the use of $Q-f$ droop control, expressed as $\omega_{w t r e f}=k_{q}\left(Q_{w t}-Q_{r e f}\right)+\omega_{w t 0}$, in the WT primary control [12]-[14], the reactive power reference $Q_{\text {ref }}$ in the primary control is adjusted to regulate the offshore frequency as shown in Fig. 3, where $k_{f p}$ and $k_{f i}$ are the control parameters of the secondary frequency control, $\omega_{p c c}$ is the offshore PCC frequency and $\omega_{\text {ref }}$ is the desired offshore frequency equalling to the HVAC link frequency. When $\omega_{p c c}<\omega_{r e f}$, the secondary frequency control produces a reduced $Q_{r e f}$ in the centralized controller, which is then sent to all the WT converters by low bandwidth communication. Consequently, the $Q-f$ droop control in the WT primary control leads to the increase of each WT generated frequency. As a result, offshore PCC frequency $\omega_{p c c}$ is also increased until becoming identical to the reference $\left(\omega_{p c c}=\omega_{r e f}\right)$. Similarly, when $\omega_{p c c}>\omega_{\text {ref }}$, offshore PCC frequency is decreased to the reference by the combined functions of secondary frequency control and $Q-f$ droop control in the primary control.

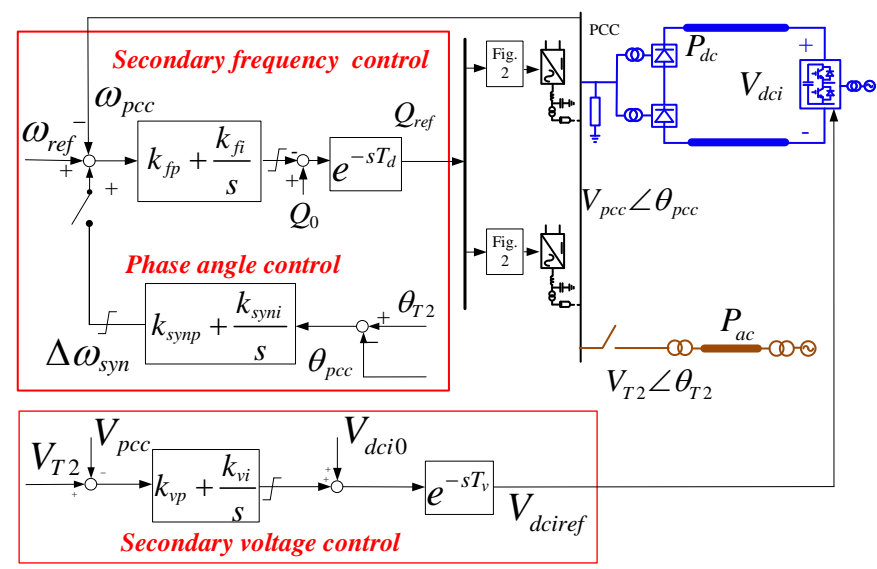

Fig. 3 Proposed secondary control of WT converters.

\section{Phase matching}

A phase angle control is proposed in this paper by adding an adjustment term $\Delta \omega_{\text {syn }}$ to the frequency reference in the secondary offshore frequency control block as shown in Fig. 3, where $k_{\text {synp }}$ and $k_{s y n i}$ are the control parameters of the active synchronization control, $\theta_{T 2}$ and $\theta_{p c c}$ are the voltage phase angles at the HVAC link and offshore PCC. As seen, when $\theta_{T 2}>\theta_{p c c}$, the phase angle control produces a positive $\Delta \omega_{\text {syn }}$, leading to the increase of offshore PCC frequency $\omega_{p c c}$. Consequently, $\theta_{p c c}$ is also increased until becoming identical to the reference $\left(\theta_{p c c}=\theta_{T 2}\right)$. Similarly, when $\theta_{T 2}<\theta_{p c c}$, offshore PCC phase angle $\theta_{p c c}$ is decreased until $\theta_{p c c}=\theta_{T 2}$.

\subsection{Proposed Tertiary Power Flow Control}

For the parallel transmission system, one particular challenge is power flow distribution between the two links. 
This paper is a post-print of a paper submitted to and accepted for publication in IET Renewable Power Generation and is subject to Institution of Engineering and Technology Copyright. The copy of record is available at IET Digital Library.

In [22], a phase-angle based active power control is implemented in offshore MMC to control power flow when an MMC-HVDC link operates in parallel with an HVAC link. In case of DR-HVDC, the DR is unable to control power flow and thus, power flow control is designed as a tertiary control in the WT centralized controller to actively adjust the phase angle difference between the offshore and onshore AC voltages connected by the HVAC link.

As illustrated in Fig. 4, the tertiary power flow control can operate on either AC active power control or DC active power control. $P_{a c r e f}$ and $P_{a c}$ are the reference and measured HVAC link active power, $P_{d c r e f}$ and $P_{d c}$ are the reference and measured HVDC link active power, respectively, $\omega_{0}$ is the rated offshore frequency. In order to achieve smooth transition between AC active power control and DC active power control, the output of DC active power control is used as the lower limit of the $\mathrm{AC}$ active power control mode.

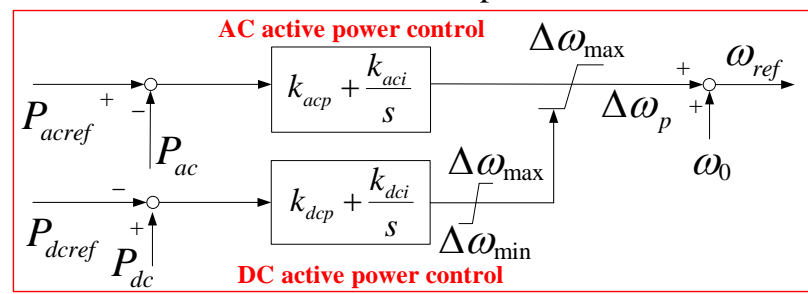

Fig. 4 Proposed AC active power control and DC active power control.

\section{A. AC active power control under parallel mode}

Under low wind conditions when the total generated wind power $P_{w t t}$ is smaller than the rated power of the DRHVDC link $P_{d c r e f}$, DC power control saturates (its output during saturation is $\Delta \omega_{\min }$ ) and the tertiary control works on AC power control mode. Thus, through the regulation of the offshore PCC phase angle, the HVAC link power is controlled to follow its reference $P_{\text {acref }}$ at 0 while all the wind power is transmitted through the DR-HVDC link. When the generated wind power changes, the controller keeps the offshore PCC phase angle largely unchanged while the offshore PCC voltage magnitude changes automatically to adjust the DR-HVDC active power transmission. If required, the $P_{\text {acref }}$ can also be set at a desired value to ensure certain power sharing between the AC and DC links.

\section{B. DC active power control under parallel mode}

Under high wind conditions, when the generated power $P_{w t t}$ exceeds the capacity of the DR-HVDC link $P_{d c r e}$, DC power control starts to de-saturate and the corresponding output starts to increase. As a result, AC power control saturates while the power flow between the two links is regulated by the DC active power control with reference $P_{d c r e f}$ at rated value to avoid any overload of DR-HVDC link. When the generated wind power changes, the controller regulates the offshore PCC phase angle to ensure that the surplus wind energy is transmitted through the HVAC link.

\section{Proposed virtual DC power control during the} transition from HVAC mode to parallel mode

For smooth transition from HVAC mode to parallel mode, active power transmitted through DR-HVDC link should remain largely unchanged before and immediately after the mode change so as to minimise any transients to the offshore networks. During HVAC mode operation, the DRHVDC link is disconnected and does not transmit any power. Therefore, to ensure smooth transition, DR-HVDC active power should remain at 0 immediately after connecting the DR-HVDC link, i.e. switching from HVAC mode to parallel mode.

According to (1) and (2), the transmitted active power through DR-HVDC link $P_{d c}$ after the connection of DRHVDC link is

$$
P_{d c}=\frac{\left(2.7 T_{d r} V_{p c c} R_{d c t}+\frac{6}{\pi} X_{d r} V_{d c i}\right)\left(2.7 T_{d r} V_{p c c}-V_{d c i}\right)}{\left(R_{d c t}+\frac{6}{\pi} X_{d r}\right)^{2}} .
$$

To ensure DC power remains at 0 after the mode transition, the "virtual DC power" concept is proposed, which considers a virtual DR-HVDC link is connected with the offshore network under HVAC mode. Thus, the virtual DC power can also be described by (5), which resembles the DRHVDC transmitted power when the DC link is switched in. A virtual DC power control can then be designed, similar to the one in the tertiary control shown in Fig. 4, with its power reference at 0 and feedback from the virtual DC power calculated by (5). Through the adjustment of the offshore network frequency and WT reactive power output, the PCC voltage is regulated to ensure the virtual DC power as calculated by (5) is 0 . That means the DC power after the mode transition will also remain at 0 , ensuring a smooth mode transition.

\section{Stability analysis of the system}

In order to analyse the stability of the hierarchical control for the parallel system, a small-signal model is established and eigenvalues are derive to identify the impact of control parameters on the critical modes.

\subsection{Small-signal modelling of the system}

The DR-HVDC link modelling is divided into three parts: DR, DR filter and DC cables. Three filter banks are considered, as shown in Fig. 1, i.e. reactive power compensation, low-pass filter and high-pass filter [3]. The onshore MMC is simplified as a controllable DC source [23][24].

The diode rectifier in $d q$ reference frame is represented as [25]

$$
\begin{aligned}
& V_{d c r}=\frac{6 \sqrt{3} T_{d r}\left(v_{p c c d}{ }^{2}+v_{p c c q}\right)^{0.5}-6 \omega_{d r} L_{d r} I_{d c r}}{\pi} \\
& P_{d r}=V_{d c r} I_{d c r}=1.5\left(v_{p c c d} i_{d r d}+v_{p c c q} i_{d r q}\right) \\
& Q_{d r}=V_{d c r} I_{d c r} \tan \varphi=1.5\left(-v_{p c c d} i_{d r q}+v_{p c c q} i_{d r d}\right) . \\
& \tan \varphi=\frac{(2 \mu-\sin 2 \mu)}{(1-\cos 2 \mu)} \\
& \mu=\arccos \left[1-\frac{2 \omega_{d r} L_{d r} I_{d c r}}{T_{d r} \sqrt{3\left(v_{p c c d}^{2}+v_{p c c q}^{2}\right)}}\right]
\end{aligned}
$$

where $\omega_{d r}$ is the offshore PCC frequency, $v_{p c c d}$ and $v_{p c c q}$ are the $d$ - and $q$-axis components of offshore PCC voltage $v_{p c c}$. The modelling of filter banks, HVDC cables and HVAC link is presented in the Appendix.

The dynamics of the DR-HVDC link and HVAC link described above are based on their own rotating $d q$ references, as shown in Fig. 5. In order to analyse the parallel operation when the two links are connected to the PCC, it is necessary to transform the individual rotating reference to a same 
This paper is a post-print of a paper submitted to and accepted for publication in IET Renewable Power Generation and is subject to Institution of Engineering and Technology Copyright. The copy of record is available at IET Digital Library.

reference for stability analysis. In this paper, the rotating reference of the diode-rectifier $d_{D R} q_{D R}$ is chosen as the common rotating reference.

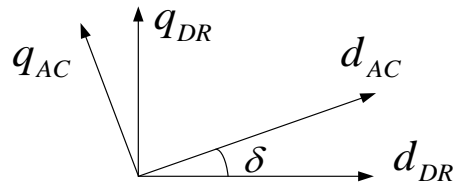

Fig. 5 Diagram of $d q$ rotating reference for DR-HVDC link and HVAC link.

Fig. 5 shows the phase angle difference of the $d q$ rotating references between the two links. The current of HVAC link transformer 2 in $d_{A C} q_{A C}$ reference frame is transformed to that based on $d_{D R} q_{D R}$ reference $i_{T 2 A C_{-} D R}$, which can be expressed as

$$
\begin{aligned}
& i_{T 2 A C_{-} D R d}=i_{T 2 d} \cos \delta-i_{T 2 q} \sin \delta \\
& i_{T 2 A C_{-} D R q}=i_{T 2 q} \cos \delta+i_{T 2 d} \sin \delta
\end{aligned} .
$$

On the other hand, the offshore PCC voltage $v_{p c c}$ in $d_{D R} q_{D R}$ reference frame needs to be converted to $d_{A C} q_{A C}$ reference $v_{p c c D R_{-} A C d q}$ using the reversed transformation as

$$
\begin{aligned}
& v_{p c c D R_{-} A C d}=v_{p c c d} \cos \delta+v_{p c c q} \sin \delta \\
& v_{p c c D R_{-} A C q}=-v_{p c c d} \sin \delta+v_{p c c q} \cos \delta
\end{aligned}
$$

The offshore wind farm consists of WT converters, transformers and AC cables. The corresponding modelling is derived using the methods presented in [26] and is not detailed in this paper. By linearizing the system at an operating point, the state space model of the parallel system is obtained. The delay $e^{-s T}$ is linearized using a third-order Pade-approximation to obtain a rational linear result [27]. Fig. 6 shows the complete small-signal model of WT converters connected with DR-HVDC link and HVAC link.

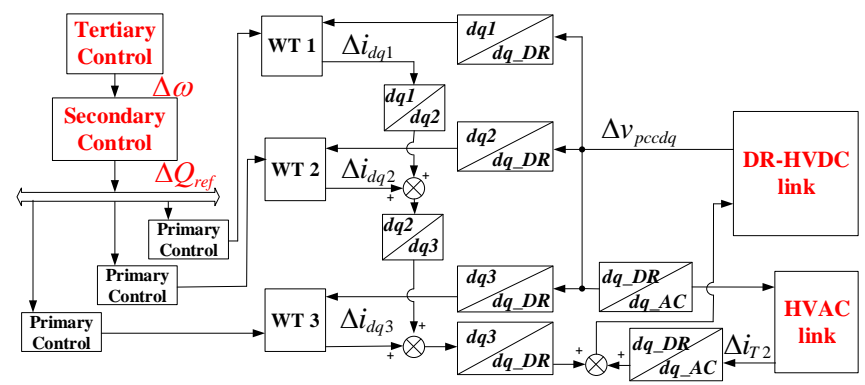

Fig. 6 Complete small-signal model of WT converters connected with DR-HVDC link and HVAC link.

\subsection{Validation of the small-signal model}

In order to validate the small-signal model, time domain performances of the small-signal model in MATLAB are compared with the simulation results in PSCAD/EMTDC under different operation modes. The system parameters are shown in Table I.

Table I Parameters of the tested parallel operation system

\begin{tabular}{|l|l|l|}
\hline Components & Parameters & Values \\
\hline \multirow{4}{*}{ DR-HVDC } & Power & $800 \mathrm{MW}$ \\
\cline { 2 - 3 } & DC voltage & $\pm 320 \mathrm{kV}$ \\
\cline { 2 - 3 } & DR transformer $(\mathrm{Y} / \mathrm{Y} / \Delta)$ & $66 / 260 / 260 \mathrm{kV}$, \\
& Leakage inductance & $0.18 \mathrm{pu}$ \\
\cline { 2 - 3 } & Reactive power compensation & $0.2 \mathrm{pu}$ \\
\hline \multirow{2}{*}{ HVAC link } & Power & $400 \mathrm{MW}$ \\
\cline { 2 - 3 } & HVAC cable length & $7 \times 5 \mathrm{~km}$ \\
\hline \multirow{3}{*}{} & Rating of aggregate WTC & $400 \mathrm{MW} \times 3$ \\
\cline { 2 - 3 } & Transformer (Y/D) & $0.69 / 66 \mathrm{kV}$ \\
& Leakage inductance & $0.08 \mathrm{pu}$ \\
\hline
\end{tabular}

\begin{tabular}{|l|l|l|}
\hline \multirow{3}{*}{ WTC } & WT Filter capacitor $C_{f}$ & $0.1 \mathrm{pu}$ \\
\cline { 2 - 3 } & Converter reactance $L_{w}$ & $0.1 \mathrm{pu}$ \\
\cline { 2 - 3 } & AC cable length (for each & $5 \mathrm{~km}, 10 \mathrm{~km}$, \\
& aggregate WT converter) & $15 \mathrm{~km}$ \\
\hline
\end{tabular}

Fig. 7 (a) compares the responses from the two models under DR-HVDC mode with the phase angle control enabled and the phase angle order increased by $0.05 \mathrm{rad}$ at $0.2 \mathrm{~s}$ (operating point: WT 1, 2 and 3 generate 100, 200 and 400 MW respectively). Under the same WT operating condition, the response under parallel mode with $\mathrm{AC}$ active power control when the power order changed from 0 to $1 \mathrm{MW}$ at 0.2 $\mathrm{s}$ is compared in Fig. 7(b). As can be seen, the performances of the small-signal model are in good agreements with the results of PSCAD/EMTDC simulation.

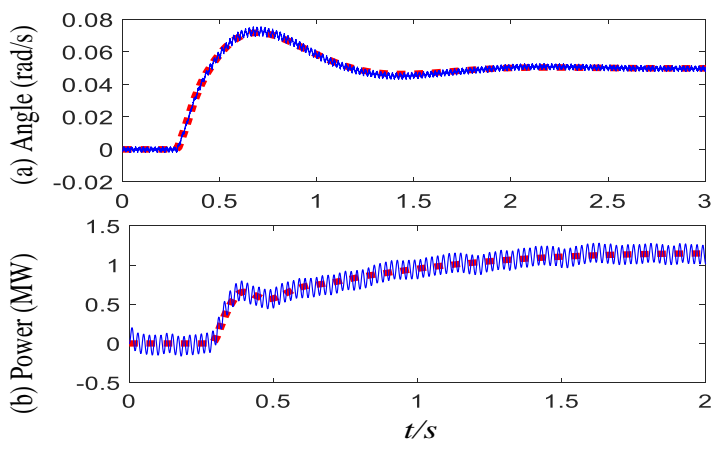

Fig. 7. Comparisons between the small-signal model (red-dot curve) and PSCAD model (blue-solid curve) under different operation modes

(a) Angle order change on DR-HVDC mode, (b) AC power order change on parallel operation mode.

\subsection{Stability analysis of the proposed control scheme}

This sub-section describes the stability analysis of the secondary control and tertiary power flow control.

The eigenvalues are derived when the secondary voltage control is enabled. Fig. 8 (a) shows the trace of the dominant eigenvalues when the communication delay $T_{v}$ increased from $0 \mathrm{~s}$ to $1.18 \mathrm{~s}$. As seen, $\lambda_{1,2}(-84.9 \pm 3.6 \mathrm{i})$ are shifted towards the right plane and eventually become evanescent modes, whereas $\lambda_{3,4}(-1.27,-4)$ become conjugated roots. When $T_{v}$ increases to $1.18 \mathrm{~s}$, the real parts of $\lambda_{3,4}$ become positive, resulting in potential system instability. Considering both system stability and practical implementation, communication delay $T_{v}$ is chosen as $0.08 \mathrm{~s}$ in this paper.

Fig. 8 (b) shows the root-loci of the closed-loop system by varying the secondary voltage control parameter $K_{v p}$ from 0 to $16\left(K_{v p} / K_{v i}\right.$ keeps constant at 0.1$)$. $\lambda_{3,4}$ move towards the left side, whereas $\lambda_{1,2}$ become less damped and eventually move to the right plane at $k_{v p}=16$. In this paper, $k_{v p}=2$ is chosen for a balance of stability and response time.

Similar studies are conducted for the secondary frequency control and phase angle control, as shown in Figs. 9 (a) and (b), respectively. $K_{w p}$ and $K_{s y p}$ are chosen as 3 and 20 respectively to achieve satisfactory response.

Fig. 10 (a) shows the movements of the dominant eigenvalues when AC power control parameter $K_{a c p}$ increased from 0 to 0.13 . $\lambda_{15,16}$ are shifted towards more stable region while $\lambda_{13,14}$ become less damped. When $K_{a c p}>0.13$, the real part of $\lambda_{13,14}$ turns to positive, resulting in potential system instability. Fig. 10 (b) shows the trace of the eigenvalues when DC power control parameter $K_{d c p}$ varies. The system 
This paper is a post-print of a paper submitted to and accepted for publication in IET Renewable Power Generation and is subject to Institution of Engineering and Technology Copyright. The copy of record is available at IET Digital Library.

can remain stable until $K_{d c p}$ is larger than 0.1 . Based on the analysis, $K_{a c p}$ and $K_{d c p}$ are both chosen as 0.05 in this study to achieve adequate damping and dynamic.

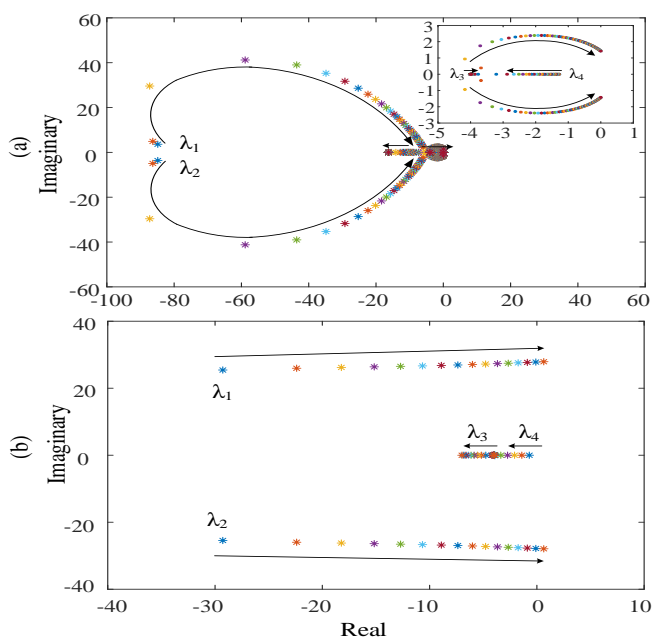

Fig. 8 Traces of eigenvalues

(a) $T_{v}$ from $0 \mathrm{~s}$ to $1.18 \mathrm{~s}$ by $0.01 \mathrm{~s},(\boldsymbol{b}) K_{v p}$ from 0 to 16 by 1

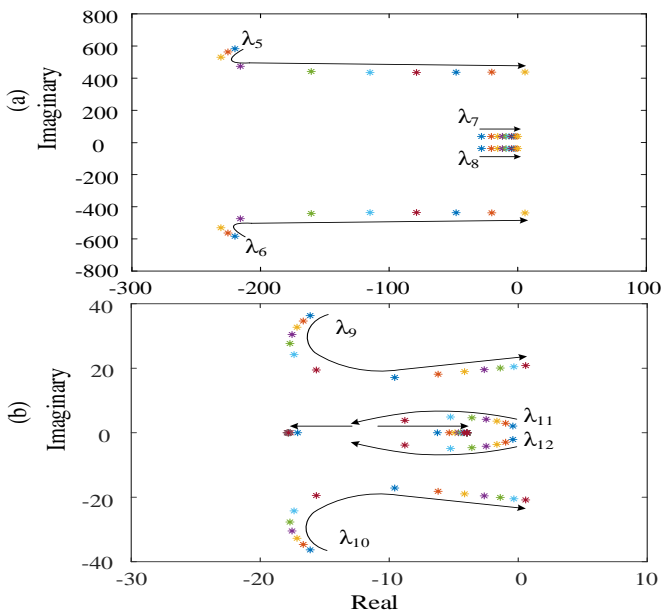

Fig. 9 Traces of eigenvalues.

(a) $K_{w p}$ from 0 to 10 by 1 , (b) $K_{\text {syp }}$ from 0 to 70 by 5 .
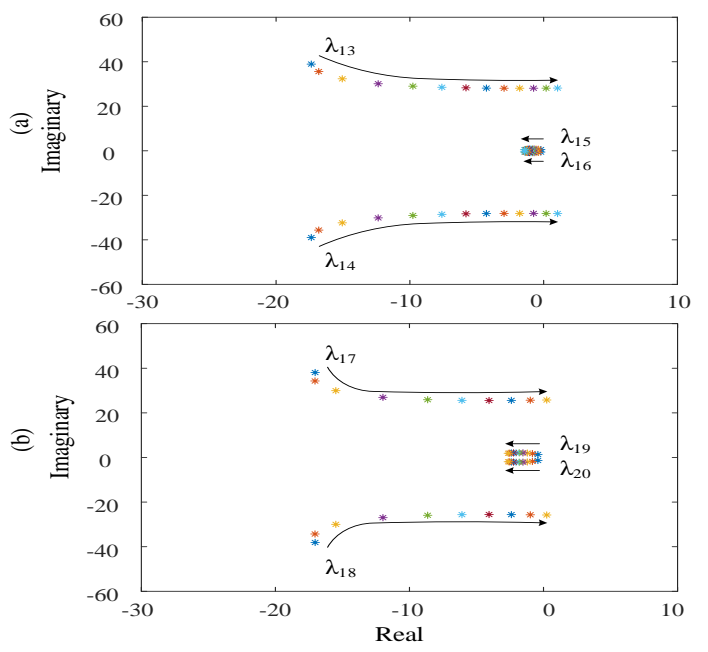

Fig. 10 Traces of eigenvalues

(a) $K_{a c p}$ from 0 to 0.13 by 0.01 , (b) $K_{d c p}$ from 0 to 0.1 by 0.01 .

\section{Simulation results}

In order to verify the operation of offshore wind farm under different operation modes, the system shown in Fig. 1 and Table I is established in PSCAD/EMTDC. The wind farm is modelled as three aggregate 400 MW WT line-side converters.

\subsection{Transition from DR-HVDC mode to parallel mode}

Fig. 11 shows the performances during the transition from DR-HVDC mode to parallel mode.

At the beginning, the generated active power of WT 1, 2 and 3 is $100 \mathrm{MW}, 150 \mathrm{MW}$ and $400 \mathrm{MW}$ respectively under the DR-HVDC mode, as shown in Fig. 11 (a). The reactive power is well shared among the WTs at $6 \mathrm{MVAr}$ each (positive $Q_{w t}$ defined as WTs providing capacitive reactive power to the offshore AC network), as shown in Fig. 11 (b).

At $5 \mathrm{~s}$, the proposed secondary voltage control is enabled. The onshore MMC DC voltage $V_{d c i}$ is regulated from $1 \mathrm{pu}$ to $0.978 \mathrm{pu}$ and the offshore PCC voltage $V_{p c c}$ is decreased from 0.983 pu to 0.965 pu to match the HVAC link voltage $V_{T 2}$, as shown in Figs. 11 (d) and (c).

At $10 \mathrm{~s}$, the proposed secondary frequency control is initialized. The offshore frequency is decreased from $50.2 \mathrm{~Hz}$ to match the HVAC link frequency of $50 \mathrm{~Hz}$, as shown in Fig. 11 (e). Consequently, the phase angle difference $\left(\theta_{p c c}-\theta_{T 2}\right)$ between the offshore PCC voltage and HVAC link voltage keeps stable at $1.51 \mathrm{rad}$., as shown in Fig. 11 (f).

At $20 \mathrm{~s}$, the phase angle synchronization control is enabled. The phase angle difference $\left(\theta_{p c c}-\theta_{T 2}\right)$ between the offshore PCC voltage and HVAC link starts to decrease from $1.51 \mathrm{rad}$. to 0 rad., as shown in Fig. 11 (f). For illustration, Figs. 11 (h) and (i) show the instantaneous voltages of the offshore PCC and HVAC link before and after phase synchronization. As seen, after the phase synchronization, the two waveforms become closely matched.

At $30 \mathrm{~s}$, the AC breaker of the HVAC link $\mathrm{B}_{1}$ (shown in Fig. 1) is closed to connect the HVAC link with the offshore wind farm. No inrush current is observed and smooth transition from DR-HVDC mode to parallel mode is achieved, as shown in Fig. 11 (i). Meanwhile, the proposed tertiary power flow control is enabled to control the HVAC link active power at 0 . As a result, all the wind power is still transmitted through the DR-HVDC link with the HVAC link power at 0 , as illustrated in Fig. $11(\mathrm{~g})$.

At $32 \mathrm{~s}$, the secondary offshore PCC voltage control is disabled to restore the onshore MMC DC voltage to $1 \mathrm{pu}$, as seen in Fig. 11 (d). The PCC voltage also increases, resulting the increase of HVAC link reactive power $Q_{a c}$ from $0 \mathrm{MVAr}$ to $31 \mathrm{MVAr}$ and so as the reactive power provided by the 3 WTs.

WT 2 ramps its active power from $150 \mathrm{MW}$ to 300 MW from $35 \mathrm{~s}$ to $40 \mathrm{~s}$ as shown in Fig. 11 (a). With active power transmitted by the DR-HVDC link increased to rated value of $800 \mathrm{MW}$, the proposed tertiary control is automatically switched from AC active power control to DC active power control.

From $45 \mathrm{~s}$ to $50 \mathrm{~s}$, both WT 2 and 3 increase their generated wind power to rated value of $400 \mathrm{MW}$, as shown in Fig. 11 (a). Fig. 11 (g) shows the DR-HVDC link transmitted active power is controlled at $800 \mathrm{MW}$ while additional 400 MW active power is transmitted through the HVAC link due to the tertiary DC active power control. 
This paper is a post-print of a paper submitted to and accepted for publication in IET Renewable Power Generation and is subject to Institution of Engineering and Technology Copyright. The copy of record is available at IET Digital Library.
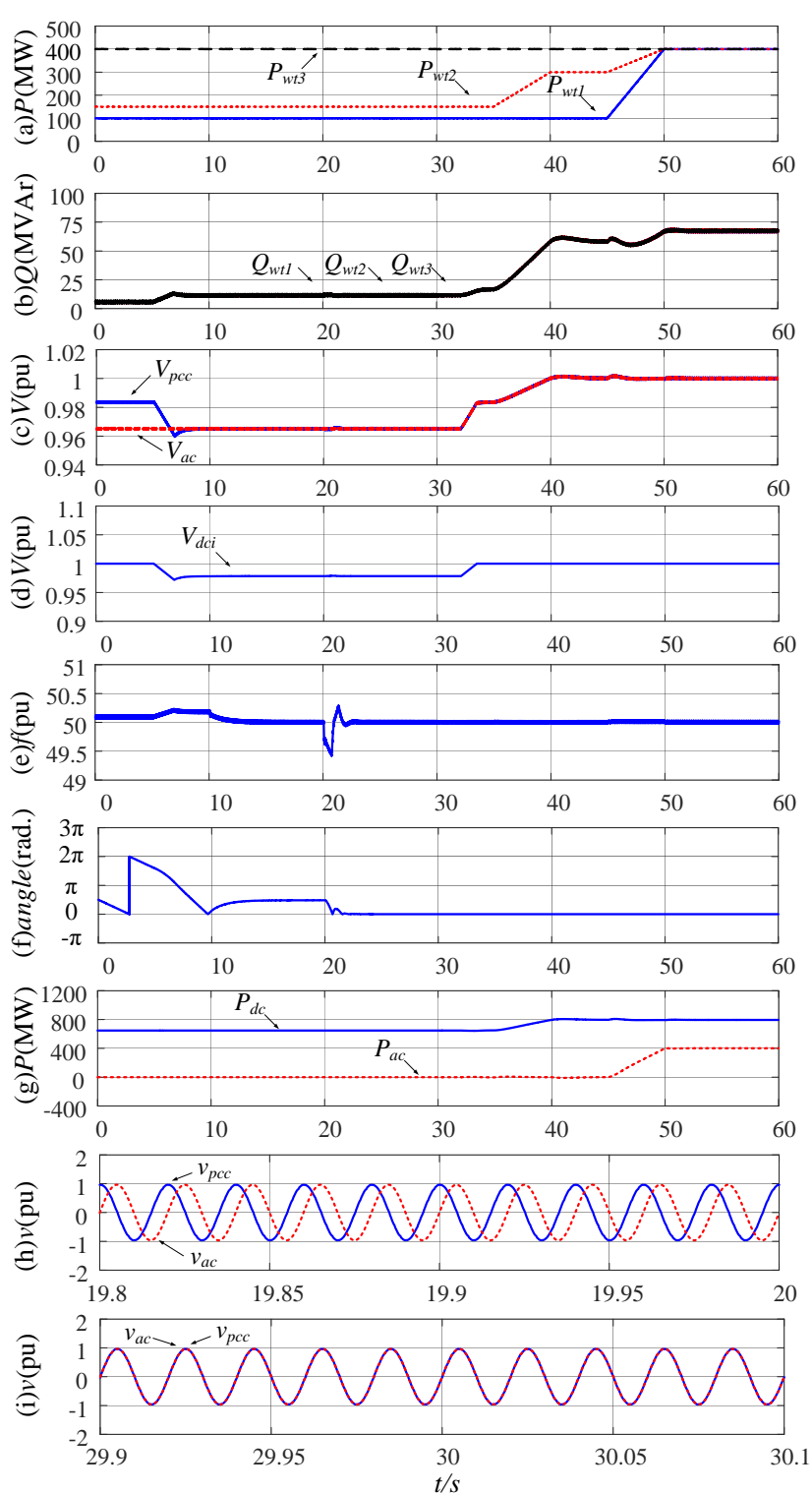

Fig. 11. Simulation results from DR-HVDC mode to parallel mode

(a) WTs active power, $(\boldsymbol{b})$ WTs reactive power, $(\boldsymbol{c})$ voltage of offshore PCC and HVAC link, (d) onshore MMC DC voltage, $(\boldsymbol{e})$ offshore frequency, $(f)$ phase angle difference between offshore PCC and HVAC link, $(g)$ transmitted active power of DR-HVDC and HVAC, $(\boldsymbol{h})$ voltages of offshore PCC and HVAC link before synchronization, $(i)$ voltages of offshore PCC and HVAC link after synchronization.

\subsection{Transition from HVAC mode to parallel mode}

The performances of the system during the transition from HVAC mode to parallel mode are illustrated in Fig. 12.

Initially, WT 1, 2 and 3 generate $50 \mathrm{MW}$ respectively on HVAC mode while reactive power of each WT converter is controlled at 0, as shown in Figs. 12 (a) and (b). From $3 \mathrm{~s}$ to $4 \mathrm{~s}$, WT 1 ramps its power from $50 \mathrm{MW}$ to $200 \mathrm{MW}$, while WT 2 and 3 active powers remain at $50 \mathrm{MW}$. Consequently, HVAC transmitted active power is increased from $150 \mathrm{MW}$ to $300 \mathrm{MW}$ as shown in Fig. 12 (e). These results indicate the primary control can well operate under HVAC mode.

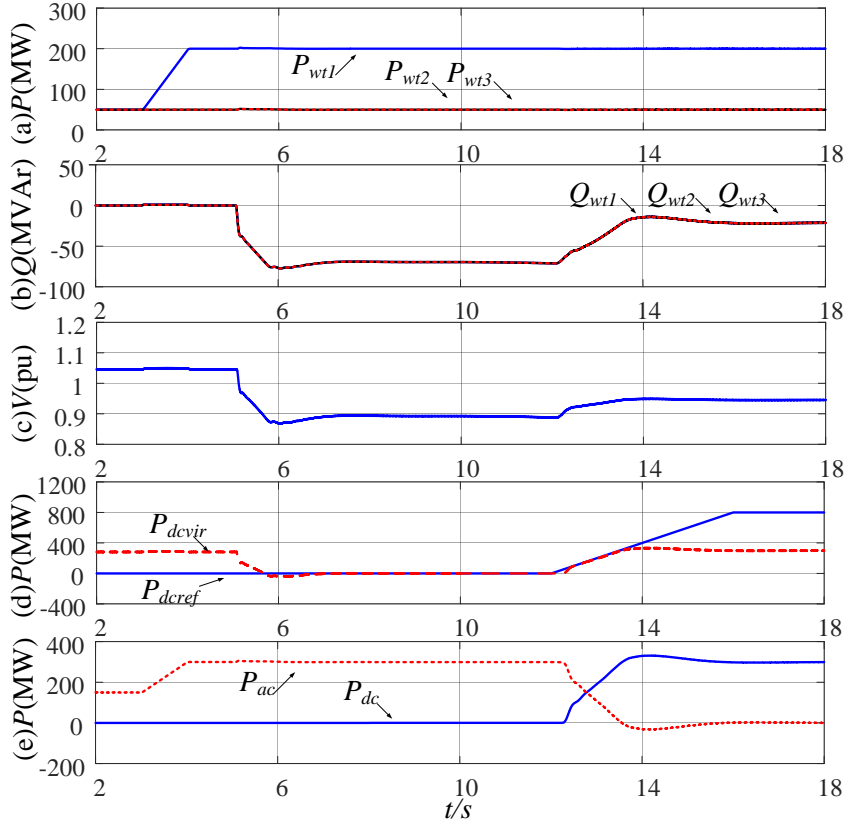

Fig. 12. Simulation results from HVAC mode to parallel mode

(a) WTs active power, (b) WTs reactive power, (c) offshore PCC voltage, $(\boldsymbol{d})$ virtual power and power reference of DRHVDC link, $(\boldsymbol{e})$ active power of DR-HVDC link and HVAC link.

At $5 \mathrm{~s}$, the proposed virtual DC power control is enabled with $P_{d c c r e f}$ at 0 pu. Figs. 12 (c) and (d) show the offshore PCC decreases from $1.046 \mathrm{pu}$ to $0.89 \mathrm{pu}$ and the virtual DC power is decreased from $280 \mathrm{MW}$ to $0 \mathrm{MW}$, respectively. Meanwhile WTs start to absorb $66 \mathrm{MVAr}$ reactive power, as shown in Fig. 12 (b).

At $8 \mathrm{~s}$, DR-HVDC link is connected to the offshore wind farm. As shown in Fig. 12 (e), smooth transition from HVAC mode to parallel mode is achieved. At $10 \mathrm{~s}$, the virtual DC power control is switched to real DC power control. From $12 \mathrm{~s}-16 \mathrm{~s}$, DC power reference is increased from $0 \mathrm{MW}$ to $800 \mathrm{MW}$, as shown in Fig. 12 (d). With the increase of DC power reference, the DC power control saturates meanwhile AC power control starts to de-saturate. As seen in Fig. 12 (e), HVAC link transmitted power is thus decreased to 0 while all wind power is transmitted to onshore grid through the DRHVDC link.

\subsection{Parallel mode to DR-HVDC mode due to $A C$ fault}

The performances of the system during the transition from parallel mode to DR-HVDC mode due to AC permanent fault are illustrated in Fig. 13. Initially, WT 1, 2 and 3 generate 100, 200, $300 \mathrm{MW}$ respectively on parallel mode while reactive power of each WT converter is controlled at 0 , as shown in Fig. 13 (d) and (e).

At $5 \mathrm{~s}$, a solid three-phase fault occurs at the middle of the HVAC link. As shown in Figs. 13 (a) and (b), voltages at the fault location $v_{a c f}$ and offshore PCC $v_{p c c}$ rapidly decrease to 0 and 0.3 pu respectively after the fault. The reduction of the offshore AC voltage leads the WT converters to decrease their active powers to around 0, as shown in Fig. 13 (d). Due to reduced offshore PCC voltage, diode-rectifier is automatically reverse-biased and no power can be transmitted through DR-HVDC link, as shown in Fig. 13 (f). Meanwhile, each WT converter operates under current-limit mode, controlling the fault current at $1.2 \mathrm{pu}$ assuming $20 \%$ 
This paper is a post-print of a paper submitted to and accepted for publication in IET Renewable Power Generation and is subject to Institution of Engineering and Technology Copyright. The copy of record is available at IET Digital Library.

overcurrent capability as seen in Fig. 13 (c). Fig.13 (e) shows that each WT converter reactive power output increases from 1 MVAr to 210 MVAr to achieve the offshore network reactive power re-balance.

At $5.15 \mathrm{~s}$, the $\mathrm{AC}$ breaker $\mathrm{B}_{1}$ (shown in Fig. 1) is opened to isolate the faulty HVAC link. As seen from the Fig. 13 (d) and (f), the wind power generation and DR-HVDC link transmission are quickly restored.

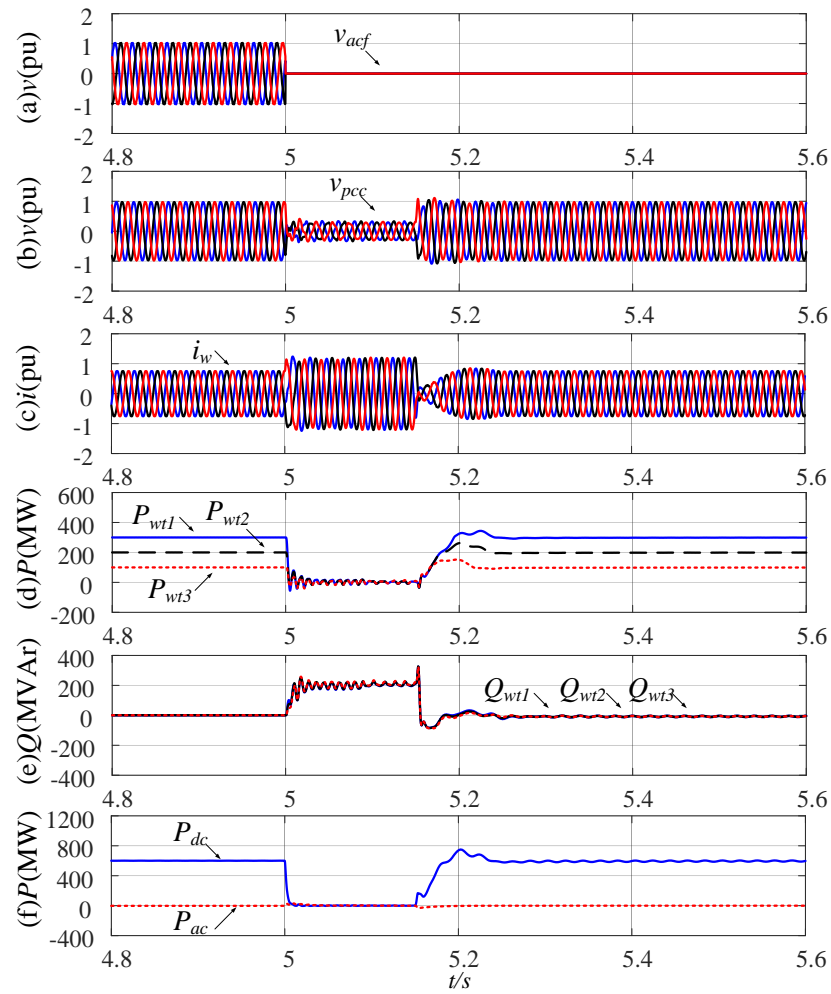

Fig. 13. Simulation results from parallel operation to DRHVDC operation mode due to HVAC link fault

(a) HVAC link AC voltage, (b) offshore PCC voltage, (c) WT current, $(\boldsymbol{d})$ WTs active power, $(\boldsymbol{e})$ WTs reactive power, $(\boldsymbol{f})$ active power of DR-HVDC link and HVAC link.

\subsection{Parallel mode to HVAC mode due to DC fault}

The performances of the system during the transition from parallel mode to HVAC mode due to DC permanent fault are illustrated in Fig. 14. Initially, WT 1, 2 and 3 generate 50, 100, $150 \mathrm{MW}$ respectively on parallel mode while reactive power of each WT converter is controlled at 20 MVAr, as shown in Figs. 14 (d) and (e).

At $10 \mathrm{~s}$, a solid DC fault occurs at the DR-HVDC link. Figs. 14 (a) and (b) show the DR-HVDC link DC voltage rapidly decreases to $0 \mathrm{pu}$ after the fault and offshore PCC voltage drops to around $0.05 \mathrm{pu}$. During the fault, the WT fault current is well controlled at $1.2 \mathrm{pu}$ as shown in Fig. 14 (c). Meanwhile, each WT converter increases its reactive power output from -20 MVAr to around $30 \mathrm{MVAr}$ to achieve the offshore network reactive power re-balance, as seen in Fig. 14 (e). Both the transmitted DC power and AC power reduce to $0 \mathrm{MW}$, as shown in Fig. 14 (f).

At 10.15 s, the AC breaker $B_{2}$ (shown in Fig. 1) opens to isolate the DR-HVDC link from the offshore network. As seen from the Fig. 6 (d) and (f), the wind power is quickly restored and transmitted through the HVAC link.
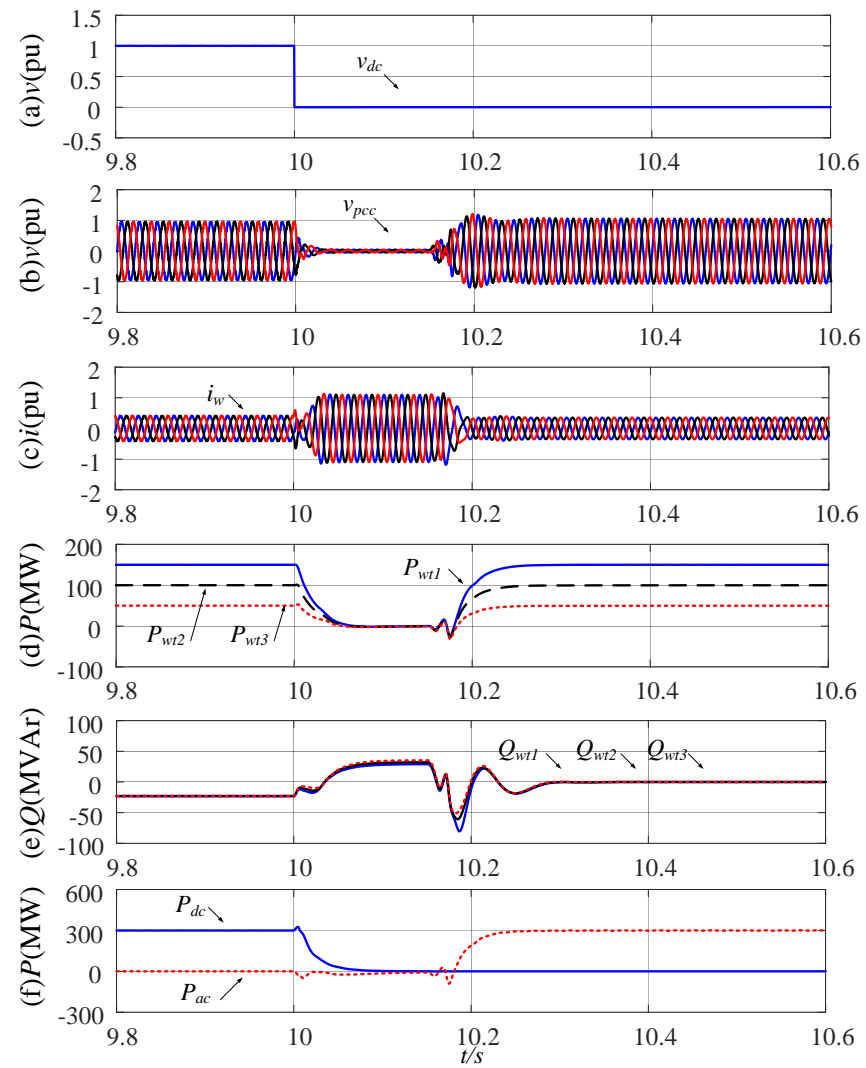

Fig. 14. Simulation results from parallel operation to HVAC operation mode due to DR-HVDC link DC fault

(a) DC voltage, (b) offshore PCC voltage, (c) WT current, $(\boldsymbol{d})$ WTs active power, $(\boldsymbol{e})$ WTs reactive power, $(\boldsymbol{f})$ active power of DR-HVDC link and HVAC link.

\section{Conclusion}

A hierarchical control of WT line-side converters, including primary control, secondary voltage, frequency, phase angle control and tertiary active power flow control, is proposed to achieve smooth operation mode switch between DR-HVDC mode, parallel mode and HVAC mode when offshore wind farm is connected to parallel DR-HVDC and HVAC links. The proposed secondary voltage control, frequency control and phase angle control enable seamless transition from DR-HVDC mode to parallel mode. The tertiary control regulates the power flow between DR-HVDC link and HVAC link through the modification of PCC phase angle, ensuring the required power sharing during parallel mode. The proposed virtual DC power control regulates the virtual DC power at 0 by adjusting the offshore $\mathrm{PCC}$ voltage magnitude, enabling seamless switch from HVAC mode to parallel mode. Small-signal stability analysis is carried out to design the secondary, tertiary control parameters and investigate the effect of communication delay on system performance for the centralized controller. Simulation results verify the proposed control strategy during the transition among various operation modes.

\section{Acknowledgments}

This work was supported by the European Union's Horizon 2020 research and innovation programme under Grant 691714. 
This paper is a post-print of a paper submitted to and accepted for publication in IET Renewable Power Generation and is subject to Institution of Engineering and Technology Copyright. The copy of record is available at IET Digital Library.

\section{Reference}

[1] Seman, S., Zurowski, R., Christ, T.: 'Investigation of DC Converter Nonlinear Interaction with Offshore Wind Power Park System'. EWEA Offshore Conference, Copenhagen, Denmark, Mar, 2015, pp. 1-6

[2] Menke, P.: 'Major breakthrough in DC grid access for large scale offshore wind farms'. EWEA Offshore Conference, Copenhagen, Denmark, Mar 2015, pp. 1-6

[3] Blasco-Gimenez, R., Ano-Villalba, S., RodriguezD'Derlee J., et al.:'Distributed Voltage and Frequency Control of Offshore Wind Farms Connected With a Diode-Based HVdc Link', IEEE Trans. Power Electron., 2010, 25, (12) pp. 3095-3105

[4] Blasco-Gimenez, R., Ano-Villalba, S., RodriguezD'Derlee J., et al.:'Diode-Based HVdc Link for the Connection of Large Offshore Wind Farms', IEEE Trans. Energy Convers., 2011, 26, (2), pp. 615-626

[5] Bernal-Perez, S., Ano-Villalba, S., Blasco-Gimenez, R., et al. : 'Efficiency and Fault Ride-Through Performance of a Diode-Rectifier- and VSC-Inverter-Based HVDC Link for Offshore Wind Farms', IEEE Trans. Ind. Electron., 2013, 60, (6), pp. 2401-2409

[6] Blasco-Gimenez, R., Aparicio, N., Ano-Villalba, S., et al.:'LCC-HVDC Connection of Offshore Wind Farms With Reduced Filter Banks', IEEE Trans. Ind. Electron., 2013, 60, (6), pp. 2372-2380

[7] Bernal-Perez, S., Ano-Villalba, S., Blasco-Gimenez, R., et al. :'Connection of off-shore wind power plants to VSCMTdc networks using HVdc diode-rectifiers', 2013 IEEE International Symposium on Industrial Electronics, Taipei, May 2013, pp. 1-6

[8] Bernal-Perez, S., Ano-Villalba, S., Blasco-Gimenez, R., et al. :'Wind power plant control for the connection to multiterminal HVdc links', 2012 IEEE Energy Conversion Congress and Exposition (ECCE), Raleigh, US, Sep, 2012, pp. 2873-2879

[9] Vidal-Albalate, R., Peña, R., Belenguer, E., et al.: 'Simultaneous connection of type-3 and type-4 off-shore wind farms to hvdc diode rectifier units'. Proceedings of the 15th Wind Integration Workshop, Vienna, Australia, Nov, 2016, pp. 1-6

[10] Prignitz, C., Eckel, H. G., Achenbach, S., et al.: 'FixReF: A control strategy for offshore wind farms with different WTtypes and diode rectifier HVDC transmission'. 2016 IEEE 7th International Symposium on Power Electronics for Distributed Generation Systems (PEDG), Vancouver, Canada, Jun 2016, pp. 1-7

[11] Cardiel-Álvarez, M. Á., Arnaltes, S., RodriguezAmenedo, J. L.: 'Decentralized Control of Offshore Wind Farms Connected to Diode-Based HVdc Links'. IEEE Trans. Energy Convers., 2018, 33, (3), pp. 1233-1241

[12] Yu, L., Li, R., Xu, L.: 'Distributed PLL-based Control of Offshore Wind Turbine Connected with Diode-Rectifier based HVDC Systems', IEEE Trans. Power Del., 2018, 33, (3), pp. 1328-1336

[13] Li, R., Yu, L., Xu, L.: 'Offshore AC Fault Protection of Diode Rectifier Unit Based HVDC System for Wind Energy Transmission'. IEEE Trans. Ind. Electron.(early access)

[14] Li, R., Yu, L., Xu, L., et al.: 'DC fault protection of diode rectifier unit based HVDC system connecting offshore wind farms', 2018 IEEE Power and Energy Society
General Meeting, Portland, United States, Aug 2018, pp. $1-5$

[15] Nguyen, T. H., Lee, D. C., Kim, C. K.: 'A SeriesConnected Topology of a Diode Rectifier and a VoltageSource Converter for an HVDC Transmission System', IEEE Trans. Power Electron., 2014, 29, (4), pp. 15791584

[16] Menke, P., Zurowski, R., Christ, T., et al.: '2nd Generation DC Grid Access for Large Scale Offshore Wind Farms', Proceedings of the 14th Wind Integration Workshop, Brussels, Belgium, Oct 2015, pp. 1-6

[17] Seman, S., Zurowski, R., Taratoris, C.: 'Interconnection of advanced Type 4 WTGs with Diode Rectifier based HVDC solution and weak AC grids'. Proceedings of the 14th Wind Integration Workshop, Brussels, Belgium, Oct 2015, pp. 1-6.

[18] Yu, L., Li, R., Xu., L.: 'Parallel operation of dioderectifier based HVDC link and HVAC link for offshore wind power transmission'. The 7th International Conference on Renewable Power Generation (RPG2018), Copenhagen, Denmark, Sep 2018, pp. 1-6.

[19] Szechtman, M. Wess, T. and Thio, V. C.: 'First benchmark model for HVDC control studies'. Electra, 1991, 135, (4), pp. 54-67.

[20] Marten, A., Akmatov, V., Sørensen, B. T., et al.: 'Kriegers flak-combined grid solution: coordinated crossborder control of a meshed HVAC/HVDC offshore wind power grid'. IET Renewable Power Generation, 2018, 12, (13), pp. 1493-1499,.

[21] Kraftnät, S.: 'An analysis of offshore grid connection at kriegers flak in the baltic sea'. Energinet. dk, Tech. Rep, 2009.

[22] Guan, L., Fan, X., Liu, Y., et al.: 'Dual-Mode Control of AC/VSC-HVDC Hybrid Transmission Systems With Wind Power Integrated', IEEE Trans. Power Del., 2015, 30, (4), pp. 1686-1693.

[23] Cheah-Mane, M., Sainz, L., Liang, J., et al.: 'Criterion for the Electrical Resonance Stability of Offshore Wind Power Plants Connected Through HVDC Links', IEEE Trans. Power Syst., 2017, 32, (6), pp. 4579-4589

[24] Kunjumuhammed, L. P., Pal, B. C., Gupta, R., et al.: 'Stability Analysis of a PMSG-Based Large Offshore Wind Farm Connected to a VSC-HVDC', IEEE Trans. Energy Convers., 2017, 32, (3), pp. 1166-1176

[25] Karawita, C., Annakkage, U. D.: 'Multi-Infeed HVDC Interaction Studies Using Small-Signal Stability Assessment', IEEE Trans. Power Del., 2009, 24, (2), pp. 910-918

[26] Pogaku, N., Prodanovic, M., Green, T. C.: 'Modeling, analysis and testing of autonomous operation of an inverter-based microgrid', IEEE Trans. Power Electron., 2007, 22, (2), pp. 613-625

[27]'Linearization of Models with Delays'. https://www.mathworks.com/help/slcontrol/examples/lin earization-of-models-with-delays.html, accessed 21 February 2019.

\section{Appendix}

\subsection{Modelling of diode rectifier filters}

The dynamics of diode rectifier filters in $d q$ reference, as shown in Fig. 15, are expressed as 
This paper is a post-print of a paper submitted to and accepted for publication in IET Renewable Power Generation and is subject to Institution of Engineering and Technology Copyright. The copy of record is available at IET Digital Library.

$$
\begin{aligned}
& \left\{\begin{array}{l}
C_{1} \frac{d v_{p c c d}}{d t}=-\frac{\left(R_{2}+R_{3}\right) v_{p c c d}}{R_{2} R_{3}}+\frac{v_{2 d}}{R_{2}}+\frac{v_{4 d}}{R_{3}} \\
+\omega_{d r} C_{1} v_{p c c q}-i_{1 d}-i_{2 d}+i_{\text {casumd }}-i_{d r d} \\
C_{1} \frac{d v_{p c c q}}{d t}=-\frac{\left(R_{2}+R_{3}\right) v_{p c c q}}{R_{2} R_{3}}+\frac{v_{2 q}}{R_{2}}+\frac{v_{4 q}}{R_{3}} \\
-\omega_{d r} C_{1} v_{p c c d}-i_{1 q}-i_{2 q}+i_{\text {casumq }}-i_{d r q}
\end{array}\right. \\
& \int C_{2} \frac{d v_{2 d}}{d t}=\frac{v_{p c c d}}{R_{2}}-\frac{v_{2 d}}{R_{2}}+i_{1 d}+\omega_{d r} C_{2} v_{2 q} \\
& C_{2} \frac{d v_{2 q}}{d t}=\frac{v_{p c c q}}{R_{2}}-\frac{v_{2 q}}{R_{2}}+i_{1 q}-\omega_{d r} C_{2} v_{2 q} \\
& C_{3} \frac{d v_{3 d}}{d t}=i_{1 d}+\omega_{d r} C_{3} v_{3 q} \\
& C_{3} \frac{d v_{3 q}}{d t}=i_{1 q}-\omega_{d r} C_{3} v_{3 d} \\
& \left\{\begin{array}{l}
C_{4} \frac{d v_{4 d}}{d t}=i_{2 d}+\frac{v_{p c c d}}{R_{3}}-\frac{v_{4 d}}{R_{3}}+\omega_{d r} C_{4} v_{4 q} \\
C_{4} \frac{d v_{4 q}}{d t}=i_{2 q}+\frac{v_{p c c q}}{R_{3}}-\frac{v_{4 q}}{R_{3}}+\omega_{d r} C_{4} v_{4 d}
\end{array}\right. \\
& \left\{\begin{array}{l}
L_{1} \frac{d i_{1 d}}{d t}=v_{p c c d}-v_{2 d}-v_{3 d}-R i_{1 d}+\omega_{d r} L_{1} i_{1 q} \\
L_{1} \frac{d i_{1 q}}{d t}=v_{p c c q}-v_{2 q}-v_{3 q}-R i_{1 q}-\omega_{d r} L_{1} i_{1 d}
\end{array}\right. \\
& \left\{\begin{array}{l}
L_{2} \frac{d i_{2 d}}{d t}=v_{p c c d}-v_{4 d}+\omega_{d r} L_{2} i_{2 q} \\
L_{2} \frac{d i q}{d t}=v_{p c c q}-v_{4 q}-\omega_{d r} L_{2} i_{2 d}
\end{array}\right.
\end{aligned}
$$

where $C_{l}$ is reactive power compensation capacitance; $R_{l}, C_{2}$, $C_{3}$ and $L_{1}$ are the resistance, capacitances and inductance of low frequency filter; $R_{2}, C_{4}$ and $L_{2}$ are the resistance, capacitance and inductance of high frequency filter; $v_{p c c d}$, $v_{p c c d q}, v_{2 d}, v_{2 q}, v_{3 d}, v_{3 q}, v_{4 d}$ and $v_{4 q}$ are the $d$ - and $q$-axis components of the voltages of $C_{1}, C_{2}, C_{3}$ and $C_{4} ; i_{1 d}, i_{1 q}, i_{2 d}$ and $i_{2 q}$ are the $d$ - and $q$-axis components of currents of $L_{l}$ and $L_{2} ; i_{\text {casumd }}$ and $i_{\text {casumq }}$ are the $d$ - and $q$-axis components of the current injected to the diode rectifier filter.

\subsection{Modelling of HVDC cables}

HVDC cables are represented by T-model and their dynamics are expressed as

$$
\left\{\begin{array}{l}
L_{e q} \frac{d I_{d c r}}{d t}+2 R_{d c} I_{d c r}+V_{d c c}=V_{d c r} \\
C_{d c} \frac{d V_{d c c}}{d t}=I_{d c r}-I_{d c i} \\
2 L_{d c} \frac{d I_{d c i}}{d t}+2 R_{d c} I_{d c i}+V_{d c i}=V_{d c c}
\end{array}\right.
$$

where $R_{d c}, L_{d c}$, and $C_{d c}$ are the resistance, inductance and capacitance of HVDC cable; $V_{d c c}$ and $V_{d c i}$ are the DC voltage of DC capacitor and onshore inverter; $I_{d c i}$ is the DC current of onshore inverter; $L_{e q}$ is the equivalent inductance and equals to $2 L_{d c}+2 B L_{d r}$.

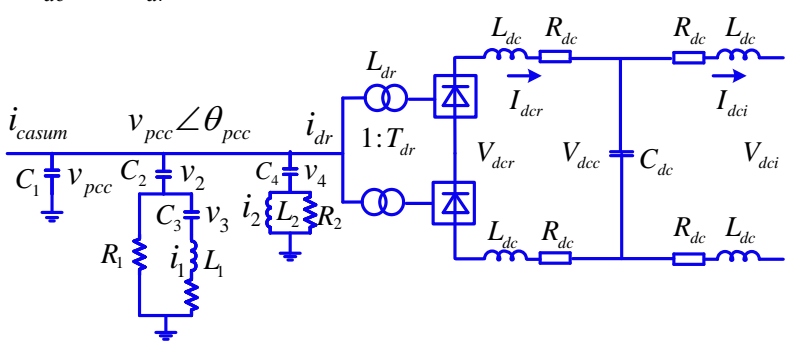

\subsection{Modelling of HVAC link}

HVAC link modelling is divided into three parts: onshore grid with transformer 1, HVAC cables and offshore transformer 2, as shown in Fig. 16. The dynamics of onshore grid with transformer 1 are expressed as

$$
\left\{\begin{array}{l}
\left(L_{\text {on }}+L_{T 1}\right) \frac{d i_{\text {ond }}}{d t}=\omega\left(L_{\text {on }}+L_{T 1}\right) i_{\text {onq }}+\frac{v_{c a 1 d}}{T_{a c 1}}-v_{\text {ond }}-R_{\text {on }} i_{\text {ond }} \\
\left(L_{\text {on }}+L_{T 1}\right) \frac{d i_{\text {onq }}}{d t}=-\omega\left(L_{\text {on }}+L_{T 1}\right) i_{\text {ond }}+\frac{v_{c a 1 q}}{T_{a c 1}}-v_{\text {onq }}-R_{\text {on }} i_{\text {on }}
\end{array}\right.
$$

where $R_{o n}, L_{o n}$ and $L_{T l}$ are the resistance, grid inductance and transformer 1 inductance; $i_{\text {ond }}$ and $i_{\text {onq }}$ are the $d$ - and $q$-axis components of onshore grid current; $v_{\text {cald }}, v_{\text {calq }}, v_{\text {ond }}$ and $v_{\text {onq }}$ are the $d$ - and $q$-axis components of HVAC cable capacitor voltage and grid voltage. $T_{a c l}$ is the ration of the transformer 1 .

HVAC cable is represented by $7 R-L-C \pi$ sections. When two $\pi$ sections are connected in series, two parallel capacitors at joint can be regarded as one capacitor with twice the original value. The modelling of HVAC cable and transformer 2 can be extended from one AC cable $\pi$ section. The dynamic of one $R-L-C \pi$ sections is expressed as

$$
\begin{aligned}
& \left\{\begin{array}{l}
C_{c a 1} \frac{d v_{c a 1 d}}{d t}=\omega C_{c a 1} v_{c a 1 q}+\frac{i_{\text {ond }}}{T_{a c 1}}-i_{c a 1 d} \\
C_{c a 1} \frac{d v_{c a 1}}{d t}=-\omega C_{c a 1} v_{c a 1 d}+\frac{i_{\text {onq }}}{T_{a c 1}}-i_{c a 1 q}
\end{array}\right. \\
& \left\{\begin{array}{l}
L_{c a 1} \frac{d i_{c a 1 d}}{d t}=\omega L_{c a 1} i_{c a 1}+v_{c a 2 d}-v_{c a 1 d}-R_{c a 1} i_{c a 1 d} \\
L_{c a 1} \frac{d i_{c a 1}}{d t}=-\omega L_{c a 1} i_{c a 1 d}+v_{c a 2 q}-v_{c a 1 q}-R_{c a 1} i_{c a 1} q
\end{array}\right.
\end{aligned}
$$

where $R_{c a l}, C_{c a l}$ and $L_{c a l}$ are the resistance, capacitance and inductance of first AC cable $\pi$ section; $i_{c a l d}$ and $i_{\text {calq }}$ are the $d$ and $q$-axis components of cable inductance current; $v_{c a 2 d}$ and $v_{c a 2 q}$ are the $d$ - and $q$-axis components of second $\pi$ section cable capacitor voltage. The modelling of transformer 2 is similar to transformer 1 and is not detailed here.

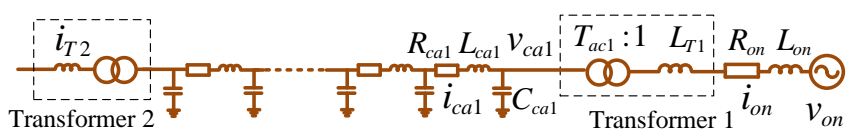

Fig. 16. Diagram of HVAC link.

Fig. 15. Diagram of DR-HVDC link. 